\title{
Sekiz bölmeli kolistinli agar besiyerinde acinetobacter baumannii türlerinde kolistin direncinin saptanması
}

\section{Determining colistin resistance in acinetobacter baumannii species in eight-compartment colistin agar medium}

\author{
Selim GÖRGÜN*
}

Samsun Eğitim ve Araştırma Hastanesi, Samsun / TÜRKiYE

Öz

Amaç: Acinetobacter baumannii suşları sıklıkla çoklu ilaç direnci gösteren ve mortalite oranı yüksek opurtunistik nozokomiyal patojenlerdir. Bu çalışmada, Acinetobacter klinik izolatlarında kolistin direnç paterninin tüp dilüsyon ve agar dilüsyon yöntemleriyle kıyaslamalı olarak değerlendirilmesinin yanı sıra rutin kullanımda olmayan sekiz bölmeli kolistinli agar besiyerinin performansının değerlendirilmesi amaçlanmıştır.

Gereç ve Yöntemler: Çalışmada, Samsun Eğitim ve Araştırma Hastanesi'de 2018-2019 yılları arasında çeşitli kliniklerinde yatmakta olan 104 hastadan izole edilen ve tam otomatik bakteri identifikasyon cihazında (VITEK 2, Biomerioux, France) tanımlaması yapılmış A.baumannii suşlarının kolistin direnci tüp makro dilüsyon ve agar dilüsyon yöntemleriyle saptandı. Agar dilüsyon testi, sekiz sabit bölmeli tek bir petri kutusunda ve 0,125-16 $\mu \mathrm{g} / \mathrm{ml}$ konsantrasyonda kolistin ilaveli Mueller Hinton agar besiyerinde yapıldı. The European Committee on Antimicrobial Susceptibility Testing (EUCAST) verilerine göre yorumlama yapılarak, $2 \mu \mathrm{g} / \mathrm{ml}$ ve altı minimal inhibitor konsantrasyon (MiK) değeri kolistine duyarlı suş olarak kabul edildi.

Bulgular: Çalışmaya dâhil edilen 104 suşun 68'i $(\% 65,4)$ otomatize sistemde, 66'sı $(\% 63,5)$ sıvı tüp dilüsyon testinde, 64'ü $(\% 61,5)$ agar dilüsyon testinde kolistine duyarlı olarak saptandı. Tüp dilüsyon testinde $38(\% 36,5)$ suş kolistine dirençli iken, agar dilüsyon testinde ise $40(\% 38,5)$ suş kolistine dirençli olarak tespit edildi. Direnç testinde $2 \mu \mathrm{g} / \mathrm{ml}$ ve altı kolistine duyarlı kabul edildi. Ancak seçilen örneklem grubu nedeniyle direnç testinde 0,125 ve 0,250 $\mu \mathrm{g} / \mathrm{ml}$ konsantrasyonlarda kolistin duyarlılığı görülmedi. Tüp dilüsyon yönteminde en fazla görülen MiK değeri $1 \mu \mathrm{g} / \mathrm{ml}$ iken agar dilüsyonunda en fazla görülen Mik değeri $2 \mu \mathrm{g} / \mathrm{ml}$ idi.

Sonuç: Sunduğumuz çalışmada agar ve tüp dilüsyon yöntemleri arasında anlamlı bir fark bulunamamıştır. Sekiz bölmeli tek bir kolistinli agar besiyerinde yapılan direnç çalışması sonucu laboratuvar maliyet avantajı sağlamaktadır.

Anahtar Kelimeler: Kolistin direnci; tüp dilüsyon testi; agar dilüsyon

Sorumlu Yazar*: Selim GÖRGÜN, Samsun Eğitim ve Araştırma Hastanesi, Samsun

E-mail:selimgorgun55@gmail.com

ORCID: 0000-0001-5841-591X

Gönderim:08.10.2020 Kabul: 08.02.2021

Doi: $10.18663 /$ tjcl.803042 


\begin{abstract}
Aim: Acinetobacter baumannii strains are opportunistic nosocomial pathogens that are frequently multi-drug resistant and have a high mortality rate. In this study, we aimed at evaluating the colistin resistance pattern in Acinetobacter clinical isolates through comparison using tube dilution and agar dilution methods, as well as the performance of a single petri dish with eight compartments that is not in routine use.
\end{abstract}

Material and Methods: In the study, A. baumannii, which was isolated from 104 patients hospitalized in Samsun Training and Research Hospital between 2018 and 2019 in various clinics and identified in the automatic bacteria identification device (VITEK 2, Biomerioux, France). The colistin resistance of the strains was determined by tube dilution and agar dilution methods. Agar dilution test was performed in a single petri dish with eight compartments and Mueller Hinton Agar Medium supplemented with colistin at a concentration of $0.125-16 \mu \mathrm{g} / \mathrm{ml}$. The results were interpreted according to The European Committee on Antimicrobial Susceptibility Testing (EUCAST) data, and a Minimal Inhibitory Concentration (MIC) value of $2 \mu \mathrm{g} / \mathrm{ml}$ and less was accepted as a colistin sensitive strain.

Results: Of the 104 strains included in the study, 68 (65.4\%) were sensitive to colistin in the automated system, 66 (63.5\%) in the liquid tube dilution test, and $64(61.5 \%)$ in the agar dilution test. While 38 (36.5\%) strains were resistant to colistin in the tube dilution test, 40 (38.5\%) strains were found to be resistant to colistin in agar dilution test. $2 \mu \mathrm{g} / \mathrm{ml}$ and less was accepted as sensitive to colistin in the resistance test. However, due to the chosen sample group, no colistin sensitivity was observed at 0.125 and $0.250 \mu \mathrm{g} / \mathrm{ml}$ concentrations in the resistance test. While the most seen MIC value in the tube dilution method was $1 \mu \mathrm{g} / \mathrm{ml}$, the most seen MIC value in agar dilution was $2 \mu \mathrm{g} / \mathrm{ml}$.

Conclusion: In the study, no significant difference was found between agar and tube dilution methods. The laboratory provided a cost advantage to the as a result of the resistance study performed on a single colistin agar medium with eight compartments.

Keywords: Colistin resistance; tube dilution test; agar dilution

\section{Giriş}

Acinetobacter baumannii çoklu ilaç direnci gösterebilen, üriner sistemde ve ciltte pürulan enfeksiyonlardan ventilatör kaynaklı pnömoni, menenjit ve sepsise kadar uzanan ciddi enfeksiyonlara sebep olabilen nozokomiyal bir patojendir [1]. Hastane kaynaklı suşları sıklıkla karbapenemler dâhil pek çok ilaca direnç göstermekte ve özellikle yoğun bakımda yatan hastalarda mortalite oranını arttırmaktadır [1,2]. Gelişen bu direnç nedeniyle A. baumannii suşlarının neden olduğu enfeksiyonların tedavisinde çok kısıtlı antimikrobiyaller veya bunların kombinasyonları tercih edilmektedir. Günümüzde dirençli A. baumannii suşlarına karşı kullanılan en etkili antimikrobiyal kolistindir [3]. Son zamanlarda dirençli A. baumannii suşlarının neden olduğu enfeksiyonlarda "kurtarma" tedavisi olarak giderek daha fazla kullanılmaktadır [4]. Bu suşlarda kolistin direncinin kolay ve doğru belirlenmesi önemlidir. Kolistin direncinin doğru belirlenmesi ise zordur. CLSI MiK $\leq 2 \mu \mathrm{g} / \mathrm{mL}$ altındaki suşlar için duyarlı değil orta derece duyarlı tanımını kullanmakta, EUCAST ise bu konsantrasyonun altını duyarlı kabul etmektedir [5,6]. Bu konudaki zorluklar direncin belirlenmesinde kullanılan farklı yöntemlere de yansımıştır. A. baumannii için kolistin direnci otomatik bakteri tanımlama sistemlerinin yanında, Kirby Bauer disk diffüzyon yöntemi, E test, sıvı dilüsyon, agar dilüsyon ve moleküler tanı yöntemleriyle belirlenebilmektedir. Kolistin direncinin belirlenmesinde bu yöntemlerin birbirine göre avantaj ve dezavantajları bulunmaktadır [7-12].

A. baumannii türlerinde kolistin direncinin belirlenmesinde CLSI ve EUCAST Tüp dilüsyon yöntemini önermektedir [5,6]. Tüp dilüsyon yönteminde Mueller Hinton Broth hazırlanmış tüplere eklenmiş farklı konsantrasyonlarda kolistine maruz bırakılan bakterilerin üreme durumları kontrol edilir. Bu yönteme benzer sonuçlar veren Agar dilüsyon yönteminde ise farklı konsantrasyonlarda hazırlanmış kolistin ilaveli Mueller Hinton besiyeri dökülmüş petri kutularında bakteri üreme durumu incelenerek antibakteriyelin direnci hakkında bilgi edinilmektedir [7-12].

Tüp dilüsyon yönteminin çalışma ve değerlendirme zorluğunun 
yanında agar dilüsyon testinini tek petride hazırlanarak çalışılması ekonomik değildir. Çalışmada, A. baumannii klinik izolatlarında kolistin direnç paterninin tüp dilüsyon ve agar dilüsyon yöntemleriyle kıyaslamalı olarak değerlendirilmesi yanı sıra rutin kullanımda olmayan sekiz bölmeli petri kutusunda hazırlanan agar dilüsyon testinin laboratuvarda rutin çalışmaya dâhil edilmesinin araştırılması amaçlanmıştır.

\section{Gereç ve yöntemler}

Sağlık Bilimleri Üniversitesi, Samsun Eğitim ve Araştırma Hastanesi Mikrobiyoloji laboratuvarında çeşitli klinik örneklerden izole edilen ve tam otomatik bakteri tanımlama ve antibiyogram cihazında (VITEK 2, Biomerioux, France) tanımlaması yapılan 104 farklı hastadan izole edilen $A$. baumannii suşun kolistin direnci 0,125, 0,250, 0,5, 1, 2, 4, 8 ve 16 $\mu \mathrm{g} / \mathrm{ml}$ konsantrasyonlarda kolistin ilaveli Mueller Hinton agar besiyeri içeren sekiz sabit bölmeli petri kutularında araştırıldı. Besiyeri hazırlanmasında; beef extract $2 \mathrm{~g}$, kazein asit pepton $17,5 \mathrm{~g}$, nişasta 1,5 g, agar agar 17,0 g ve kolistin'in 0,125-16 $\mu \mathrm{g} /$ $\mathrm{ml}$ konsantrasyonları eklenerek pH değeri 7,3'e ayarlandı. Bu çalışma için özel olarak dizayn edilen sabit sekiz bölmeli petri kutularına (Şekil 1) besiyeri dökülerek hazırlandı.
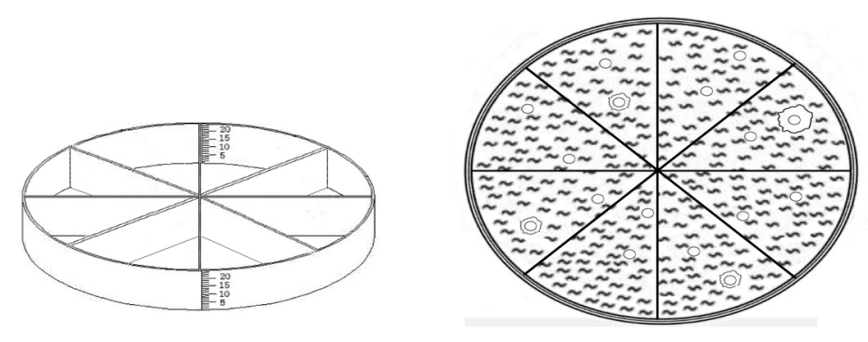

Şekil 1. Sekiz bölmeli petri kutusu A) Üç boyutlu görünüş B) Üstten görünüş.

Derin dondurucuda $-80^{\circ} \mathrm{C}$ de stok besiyerinde saklanan $104 \mathrm{klinik}$ A. baumannii suşu ve bir adet kalite kontrol suşu (A. baumannii 19606 ATCC) \%5 koyun kanlı agar (GBL, Türkiye) ve Eosin Methylene Blue agar besiyerlerine (GBL, Türkiye) pasajlandı. Ekimler 24 saat $37^{\circ} \mathrm{C}$ 'de inkübe edildi. Üreme gösteren bakteri kolonilerinden 0,5 McFarland bulanıklığa ayarlanan (108 bakteri/ml) bakteri süspansiyonları dilüe edilerek inokulumda 104 bakteri olacak şekilde $10 \mu$ lt miktarda kolistinli sekiz bölmeli besiyerlerine ekimleri yapıldı [13]. Besiyerleri 24 saat inkubasyon sonrasında EUCAST kriterlerine göre değerlendirildi [12,13]. MiK değeri $2 \mu \mathrm{g} / \mathrm{ml}$ ve altında olan A. baumannii suşları kolistin duyarlı kabul edildi. Değerlendirme sırasında kolistin içermeyen kontrol besiyerindeki üreme kontrolü için de ekim yapıldı. Suşlar için eş zamanlı olarak tüp dilüsyon yöntemi ile de kolistin direnci araştırıldı. Bunun için 0,125, 0,250, 0,5, 1, 2, 4, 8 ve $16 \mu \mathrm{g} / \mathrm{ml}$ konsantrasyonlarda kolistin ilaveli sekiz tüpe ekimler yapıldı. Tüp dilüsyon yapılarak hazırlanan duyarlılık testi 24 saat inkübasyon sonrası değerlendirilerek MiK değerleri saptandı.Çalışma için 27.05.2020 tarih ve 2020/7 sayılı yerel etik kurulu izni alınmıştır.

\section{Bulgular}

Çalışmaya dâhil edilen 104 A. baumannii suşunun 68'i $(\% 65,4)$ otomatize sistemde kolistin duyarlı $(<=0.500 \mu \mathrm{g} / \mathrm{m})$ suşlardı. Bu suşlardan 66 'sı $(\% 63,5)$ tüp dilüsyon testinde ve $0,5 \mu \mathrm{g} / \mathrm{ml}$ (8 suş), $1 \mu \mathrm{g} / \mathrm{ml}$ (31 suş), $2 \mu \mathrm{g} / \mathrm{ml}$ (27 suş) konsantrasyonlarda duyarlı olarak saptandı. Otomatize sistemde duyarlı saptanan iki suş $(\% 1,9)$ tüp dilüsyon testinde $4 \mu \mathrm{g} / \mathrm{ml}$ ve $8 \mu \mathrm{g} / \mathrm{ml}$ MiC değerinde dirençli olarak saptanmıştır.

Çalışmaya dahil edilen A.baumannii suşlarının 36'si $(\% 34,6)$ otomatize sistemde kolistin dirençli $(>2 \mu \mathrm{g} / \mathrm{m}$ ) suşlardı. Bu suşların tümü, tüp dilüsyon yönteminde $4 \mu \mathrm{g} / \mathrm{ml}$ (10 suş), 8 $\mu \mathrm{g} / \mathrm{ml}$ (6 suş), $16 \mu \mathrm{g} / \mathrm{ml}$ (22 suş) konsantrasyonlarda dirençli olarak saptandı.

Tüp dilüsyon yönteminde duyarlı saptanan suşlar (n:66) sekiz bölmeli agar dilüsyon testinde $0,5 \mu \mathrm{g} / \mathrm{ml}$ (6 suş), $1 \mu \mathrm{g} / \mathrm{ml}$ (28 suş), $2 \mu \mathrm{g} / \mathrm{ml}$ (30 suş) konsantrasyonlarda toplamda 64 suş kolistine duyarlı saptandı. Tüp dilüsyon testinde dirençli saptanan suşlar sekiz bölmeli agar dilüsyon testinde $4 \mu \mathrm{g} / \mathrm{ml}$ (12 suş), $8 \mu \mathrm{g} / \mathrm{ml}$ (4 suş), $16 \mu \mathrm{g} / \mathrm{ml}$ (24 suş) konsantrasyonlarda dirençli olarak saptandı. Tüp dilüsyon testinde duyarlı saptanan iki suş $(\% 1,9)$ sekiz bölmeli agar dilüsyon testinde $4 \mu \mathrm{g} / \mathrm{ml}$ MiK değerinde dirençli saptanmıştır. Çalışmaya dâhil edilen suşlar içinde seçilen örneklem grubu nedeniyle 0,125 ve 0,250 $\mu \mathrm{g} / \mathrm{ml}$ konsantrasyonlarda kolistin duyarlılığı görülmedi. Tüp dilüsyon yönteminde en fazla görülen MiK değeri $1 \mu \mathrm{g} / \mathrm{ml}$ iken agar dilüsyonunda en fazla görülen MiK değeri $2 \mu \mathrm{g} / \mathrm{ml}$ idi. (Tablo 1) Mik dağılımları açısından gruplar arasında anlamlı farklılık bulunmuştur $(p<0,001)$. Farklılığı oluşturan değerler koyu renkle gösterilmiştir. Örneğin; VITEK 2 yöntemiyle 0,5 $\mu \mathrm{g} /$ $\mathrm{ml}$ MiK değerine sahip olduğu saptanan izolat oranı $(\% 65,4)$ diğer yöntemlerle $0,5 \mu \mathrm{g} / \mathrm{ml}$ olduğu saptanan izolat oranlarına $(\% 7,7$ ve \%5,8) göre anlamlı yüksek bulunmuştur. (Tablo 1)

Yaptığımız çalışmada VITEK 2'ye ait ortalama MiK değerleri diğer iki gruba göre anlamlı düşük bulunmuştur (Sıvı dilüsyona göre $p=0,002$; agar dilüsyona göre $p<0,001$ ). Sıvı ve agar dilüsyon sonuçları kendi aralarında benzer bulunmuştur $(p=0,641)$ (Tablo 2). 


\begin{tabular}{|c|c|c|c|c|}
\hline & VITEK 2 & Sıvı dilüsyon & Agar dilüsyon & $p$ \\
\hline MiK $(\mu \mathrm{g} / \mathrm{ml})$ & & & & $<0,001$ \\
\hline 0.125 & 0 & 0 & 0 & - \\
\hline 0.25 & 0 & 0 & 0 & - \\
\hline 0.5 & $68(65,4)$ & $8(7,7)$ & $6(5,8)$ & $<0,001$ \\
\hline 1 & 0 & $31(29,8)$ & $28(26,9)$ & $<0,001$ \\
\hline 2 & 0 & $27(26)$ & $30(28,8)$ & $<0,001$ \\
\hline 4 & $8(7,7)$ & $10(9,6)$ & $12(11,5)$ & 0,642 \\
\hline 8 & $4(3,8)$ & $6(5,8)$ & $4(3,8)$ & 0,741 \\
\hline 16 & $24(23,1)$ & $22(21,1)$ & $24(23,1)$ & 0,929 \\
\hline Duyarlılık & & & & 0,847 \\
\hline$S$ & $68(65,4)$ & $66(63,5)$ & $64(61,5)$ & \\
\hline $\mathrm{R}$ & $36(34,6)$ & $38(36,5)$ & $40(38,5)$ & \\
\hline \multicolumn{5}{|c|}{ S: Duyarlı, R: Dirençli. } \\
\hline
\end{tabular}

$\begin{aligned} & \text { Tablo 2. Yöntemler arasında geometrik ortalama değerleri } \\ & \text { açısından karşılaştırma (ortalama } \pm \text { standart sapma). }\end{aligned}$
$\begin{array}{lcc}\text { Grup } & \text { Ort. } \log 2(2 \text { üzeri) } & \text { Ort. MiK* }(\mu \mathrm{g} / \mathrm{ml}) \\ \text { Vitec } & 0,54 \pm 2,181 & 1,45 \pm 4,53 \\ \text { SıVı } & 1,39 \pm 1,645 & 2,62 \pm 3,13 \\ \text { Agar } & 1,5 \pm 1,619 & 2,83 \pm 3,07 \\ \text { *Geometrik ortalama. Ort. Ortalama. } \mathrm{p}<0,001 .\end{array}$

\section{Tartışma}

Rutinde kolistin direncinin saptanmasında; Kirby Bauer disk difüzyon yöntemi, E test, otomatik bakteri tanımlama ve antibiyogram cihazı kullanılmaktadır. Ancak bu yöntemlerde birbilerine uyumsuz sonuçlar elde edilmektedir. Bu durum da sonuçlarıyorumlayanlarda şüpheile karşılanmaktadır [7-12]. Bu nedenle EUCAST VE CLSI uygulamalarında kolistin direncinin daha doğru tespiti için tüp dilüsyon testi önerilmiştir. Ancak bu yöntemin çalışma zorluğu ve alternatif olarak geliştirilen ticari sistemlerin maliyet gerektirmeleri dezavantajlarıdır [13]. Çalışmamızda kolistin direncinin belirlenmesinde ucuz, pratik ve aynı zamanda çalışma kolaylığı sağlayan sekiz bölmeli agar dilüsyon petri kutularının laboratuvarda ilk kez kullanımı ve test performansı araştırılmıştır.

Bakteriyoloji laboratuvarında yapılan testlerle ilgili olarak daha pratik ve ekonomik kullanımlar tercih edilmektedir. Kültür yapılan testler için ise ayrı ayrı petri kutularında dökülen besiyerlerine ekimler yapılması yaygındır. Son zamanlarda kültür testleri için kullanılan besiyerlerinde iki bölmeli, üç bölmeli ve dört bölmeli petri kaplarının benzer şekilde kullanıldığı görülmektedir [14,15]. Fakat sekiz bölmeli petri kutusunda hazırlanan agar dilüsyon yöntemi ile duyarlılık testinin çalışılması henüz laboratuvarlarda kullanılmamıştır. Sekiz bölmeli petri kutusunda ilk kez bu çalışmayı gerçekleştirdik. Çalışmayı yaparken elde ettiğimiz kolistin duyarlılık sonuçlarının doğruluğunun karşılaştırılması için altın standart duyarlılık testi olan tüp dilüsyon test sonuçlarını kullandık. Yine çalışmamızda son yıllarda özellikle yoğun bakım ünitelerinin sorunu kabul edilen, güç tedavi edilebilen ve pek çok antibiyotiğe dirençli $A$. baumannii türlerini kullandık. Bu türlerin tedavisinde günümüzde kolistin en önemli tedavi seçeneklerinden biridir. Özellikle bu türlerde kolistin direncinin doğru belirlenmesi hastanın prognozu açısından daha da önemli hale gelmiştir. Çalışmamızda iki bakteri suşu otomatize sistemde duyarlı saptanmasına karşın tüp dilüsyon testinde ve alternatif olarak çalıştığımız sekiz bölmeli agar dilüsyon testinde dirençli saptanmıştır.

Çalışmamızda tüp dilüsyon testleri referans MiK değerleri ile sekiz bölmeli petride hazırlanan agar dilüsyon testleri arasında hem duyarlı hem de duyarlı olmayan suşlarda benzerlik bulunurken, duyarlıMiKsonuçlarıagardilüsyondabirlogyüksek saptanmıştır $(p<0,63)$. Bu farklılığın nedeni olarak agar dilüsyon testinde büyük kolistin moleküllerinin zayıf difüzyonunun sonuçlar üzerinde etkili olabileceği değerlendirilmiştir [7$10,16]$. İki suş $(\% 1,9)$ tüp dilüsyon testinde duyarlı olmasına rağmen agar dilüsyon testinde dirençli saptanmıştır. Ancak bu sonuçlar genelle kıyaslandığında istatistiksel olarak anlamlı saptanmadığından benzer değerlendirilmiştir.

\section{Sonuç}

Bakteriyoloji laboratuvarında birden fazla örneğin aynı anda, eş zamanlı olarak çalışılmasına imkân sağlayan tek kullanımlık sekiz bölmeli petride hazırlanan agar dilüsyon testinde çalışılan Acinetobacter suşlarının kolistin duyarlılığı tüp dilüsyon test sonuçlarına benzer saptanmıştır. Sekiz bölmeli petride ilk kez laboratuvar şartlarında kullanım için hazırladığımız agar dilüsyon testi ekonomik ve pratik olup aynı zamanda güvenilir kolistin duyarlılık sonucu vereceği düşünülmüştür. $\mathrm{Bu}$ petrilerde hazırlanan agar dilüsyon testinin kullanımı özellikle iş yükü fazla laboratuvarda aynı anda sekiz bakteriye ait kolistin duyarlılığının belirlenmesine imkân sağlayacaktır.

\section{Kaynaklar}

1. Munoz-Price LS, Weinstein RA. Acinetobacter infection. N Engl J Med. 2008; 358: 1271-81.

2. Savcı Ü, Özveren G, Bulut Y, et al. Klinik örneklerden izole edilen Acinetobacter baumannii suşlarının in-vitro duyarlılık durumları. Turk J Clin Lab. 2015; 6: 24-9 
3. Owen RJ, Li J, Nation RL et al. In vitro pharmacodynamics of colistin against Acinetobacter baumannii clinical isolates. J Antimicrob Chemother. 2007; 59: 473-7.

4. Li J, Rayner CR, Nation RL, et al. Heteroresistance to colistin in multidrug-resistant Acinetobacter baumannii. Antimicrob Agents Chemother. 2006; 50: 2946-50.

5. Arroyo LA, García-Curiel A, Pachón-lbañez ME, et al. Reliability of the E-test method for detection of colistin resistance in clinical isolates of Acinetobacter baumannii. J Clin Microbiol. 2005; 43: 903-5.

6. Lo-Ten-Foe JR, de Smet AM, Diederen BM, et al. Comparative evaluation of the VITEK 2, disk diffusion, etest, broth microdilution, and agar dilution susceptibility testing methods for colistin in clinical isolates, including heteroresistant Enterobacter cloacae and Acinetobacter baumannii strains. Antimicrob Agents Chemother. 2007; 51: 3726-30.

7. Tan TY, Ng LS, Poh K. Susceptibility testing of unconventional antibiotics against multiresistant Acinetobacter spp. by agar dilution and Vitek 2. Diagn Microbiol Infect Dis. 2007; 58: 357-61.

8. Tan TY, Ng SY. Comparison of Etest, Vitek and agar dilution for susceptibility testing of colistin. Clin Microbiol Infect. 2007; 13: 541-4.

9. Chew KL, La MV, Lin RTP, et al. Colistin and Polymyxin B Susceptibility Testing for Carbapenem-Resistant and mcrPositive Enterobacteriaceae: Comparison of Sensititre MicroScan, Vitek 2, and Etest with Broth Microdilution. J Clin Microbiol. 2017; 55: 2609-16.

10. Satlin MJ, Lewis JS, Weinstein MP, et al. Clinical and Laboratory Standards Institute (CLSI) and European Committee on Antimicrobial Susceptibility Testing (EUCAST) position statements on polymyxin B and colistin clinical breakpoints. Clin Infect Dis. 2020; 121.
11. Clinical and Laboratory Standards Institute. Performance Standards for Antimicrobial Susceptibility Testing, 30th Edition. CLSI document M100, 2020.

12. European Committee on Antimicrobial Susceptibility Testing. Breakpoint tables for interpretation of MICs and zone diameters, version 10.0, 2020.

13. Antibiyotik Duyarlılık Testleri, EUCAST: Uygulama, Yorum ve Uzman Kurallar Editör: Prof. Dr. Deniz Gür Hacettepe Üniversitesi Tıp Fakültesi, Tıbbi Mikrobiyoloji Anabilim Dalı, Ankara. Türk Mikrobiyol Cem Derg. 2016; 46.

14. Singhal $L$, Sharma M, Verma $S$, et al. Comparative Evaluation of Broth Microdilution with Polystyrene and Glass-Coated Plates, Agar Dilution, E-Test, Vitek, and Disk Diffusion for Susceptibility Testing of Colistin and Polymyxin B on Carbapenem-Resistant Clinical Isolates of Acinetobacter baumannii. Microb Drug Resist. 2018; 24: 1082-88.

15. Kocagöz T. Mikrobiyolojik Tanıda Klasik Yöntemlerde Yeni Yaklaşımlar. ANKEM Derg. 2013; 27:150-3.

16. MatuschekE, Åhman J, Webster C, et al. Antimicrobial susceptibility testing of colistin- evaluation of seven commercial MIC products against standard broth microdilution for Escherichia coli, Klebsiella pneumoniae, Pseudomonas aeruginosa, and Acinetobacter spp. Clin Microbiol Infect. 2018; 24: 865-70. 